\title{
Editorial: Host-Guest Chemistry of Macrocycles
}

\author{
Tangxin Xiao ${ }^{1 *}$, Robert Elmes ${ }^{2,3 *}$ and Yong Yao ${ }^{4 *}$ \\ ${ }^{1}$ School of Petrochemical Engineering, Changzhou University, Changzhou, China, ${ }^{2}$ Department of Chemistry, \\ Maynooth University, National University of Ireland, Maynooth, Ireland, ${ }^{3}$ Synthesis and Solid-State Pharmaceutical \\ Centre, Maynooth University, National University of Ireland, Maynooth, Ireland, ${ }^{4}$ School of Chemistry and Chemical \\ Engineering, Nantong University, Nantong, China
}

Keywords: macrocycles, supramolecular chemistry, host-guest interaction, self-assembly, pillar[n]arenes

\section{Editorial on the Research Topic}

\section{Host-Guest Chemistry of Macrocycles}

Macrocycle-based host-guest chemistry has played an important role in the development of supramolecular chemistry. Burgeoning progress has been continuously made in the development of supramolecular assemblies by using various host molecules, such as cyclodextrins (Li and Purdy, 1992; Szejtli, 1998; Harada et al., 2009, 2014; Antoniuk and Amiel, 2016), cucurbiturils (Lagona et al., 2005; Ni et al., 2014; Barrow et al., 2015; Murray et al., 2017), calixarenes (Shinkai et al., 1984; Böhmer, 1995; Guo and Liu, 2014), crown ethers (Pedersen, 1967; Amabilino et al., 1995; Zhang et al., 2007; Xiao et al., 2020a, 2021), pillararenes (Ogoshi et al., 2008, 2016, 2018; Xue et al., 2012; Strutt et al., 2014; Kakuta and Yamagishi, 2018; Xiao et al., 2018, 2019a,b,c), and other macrocycles (Wang et al., 2019). The architectures and properties of different hosts endow

\section{OPEN ACCESS}

Edited and reviewed by: Tony D. James, University of Bath, United Kingdom

*Correspondence:

Tangxin Xiao

xiaotangxin@cczu.edu.cn

Robert Elmes

robert.elmes@mu.ie

Yong Yao

yaoyong1986@ntu.edu.cn

Specialty section:

This article was submitted to

Supramolecular Chemistry, a section of the journal

Frontiers in Chemistry

Received: 11 November 2020 Accepted: 17 November 2020 Published: 09 December 2020

Citation: Xiao T, Elmes $R$ and Yao Y (2020) Editorial: Host-Guest Chemistry of Macrocycles. Front. Chem. 8:628200. doi: 10.3389/fchem.2020.628200 themselves with versatile abilities to bind with different guest molecules. Therefore, macrocyclic hosts show significant potential in constructing assorted functional materials, such as hydrogels (Appel et al., 2012; Xiao et al., 2019d), functional supramolecular polymers (Chen et al., 2019; Xiao et al., 2020b), artificial light harvesting systems (Xiao et al., 2019e), and so on.

Supramolecular polymers, a concept combining elements of both supramolecular chemistry and polymer science, are promising dynamic functional materials. Moreover, the incorporation of fluorophores into supramolecular polymers could endow them with interesting photophysical properties. In this context, Zhang et al. reviewed fluorescent supramolecular polymers constructed by crown ether-based host-guest interactions. They focused on fabrication strategies, properties, and potential applications of these materials. On the same Topic, Wu and Xiao contributed an article on an aggregation induced emissive (AIE) supramolecular polymer which was constructed from a cyanostilbene based ditopic benzo-21-crown-7 and a ditopic dialkylammonium salt. In another review paper, Gatiatulin et al. summarized the possible alternatives to the classical key-to-lock principle with higher selectivity for molecular recognition. These alternatives are based on cooperativity of phase transitions, which adds up the small differences in molecular structure of different bound guests. In a minireview, Duan et al. (b) summarized broad approaches for the preparation of graphene nanomaterials functionalized with calix[n]arene/pillar[n] arene, and their applications in molecular recognition, fluorescent sensors, electrochemical biosensors, and as catalytic, antibacterial, and adsorption materials.

Calixarene derivatives have played an important role in developing anti-tumor agents. The contribution of An et al. focused on novel dihomooxacalix[4]arene-based antitumor agents. In their work, they reported the synthesis of 19 structurally related dihomooxacalix[4] arene amide derivatives in search of optimal efficacy. Guo et al. synthesized a p-tert-butyldihomooxacalix[4]arene, which could form a soft gel in cyclohexane. Moreover, the 
xerogel with its highly interconnected and homogeneous porous network, may be used for drug storage and controlled release. Pillararenes are a relatively new macrocyclic host and have been employed to fabricate various supramolecular materials. Macrocyclic amphiphiles have attracted much attention due to their unique properties in the construction of functional nanomaterials. The work of Wang et al. investigates a pillararene-based macrocyclic amphiphile, which is responsive to $\mathrm{pH}$. Interestingly, a $\mathrm{pH}$-induced transition between singlechain macrocyclic amphiphile and bola-type amphiphile and the corresponding self-assembly behavior was investigated. Self-assembled peptides can also be used to fabricate new biomaterials for medical applications. Duan et al. (a) developed cationic pillar[6] arene-modified graphene films on glassy carbon electrodes directly from graphene oxide-cationic pillar[6]arene dispersions using a pulsed electrodeposition technique. Experimental results revealed that the electrochemically reduced graphene oxide-cationic pillar[6]arene films could show a much higher electrochemical response to five purine bases than unmodified reduced graphene oxide films and bare glassy carbon electrodes. In other work, Duan, Wang, Zhang et al. designed new host-guest binding motifs based on a water-soluble pillar[6]arene dodecyl-ammonium chloride with two aromatic sulfonic acids in water. Interestingly, both of these host-guest complexes can be tuned reversibly between their complexed and decomplexed states by sequential addition of a base and an acid $(\mathrm{NaOH}$ and $\mathrm{HCl}$, respectively). Construction of polypseudorotaxanes in high-polar organic solvents is challenging owing to the weak interactions between macrocycles and axles. Su et al. prepared a novel metal-coordinated poly[2]pseudorotaxane by using pillar[5]arene, 1,4-bis(4-pyridyl pyridinium)butane, and $\left[\mathrm{PdCl}_{2}(\mathrm{PhCN})_{2}\right]$ in dimethyl sulfoxide.

Chaudhuri et al. developed a method to promote clean and environmentally friendly disinfection of phenolic substrates by employing $\alpha$-cyclodextrin to affect the product distribution in

\section{REFERENCES}

Amabilino, D. B., Ashton, P. R., Brown, C. L., Cordova, E., Godinez, L. A., Goodnow, T. T., et al. (1995). Molecular meccano. 2. Self-assembly of [n]catenanes. J. Am. Chem. Soc. 117, 1271-1293. doi: 10.1021/ja00109 a011

Antoniuk, I., and Amiel, C. (2016). Cyclodextrin-mediated hierarchical selfassembly and its potential in drug delivery applications. J. Pharm. Sci. 105, 2570-2588. doi: 10.1016/j.xphs.2016.05.010

Appel, E. A., del Barrio, J., Loh, X. J., and Scherman, O. A. (2012). Supramolecular polymeric hydrogels. Chem. Soc. Rev. 41, 6195-6214. doi: $10.1039 / \mathrm{C} 2 \mathrm{CS} 35264 \mathrm{H}$

Barrow, S. J., Kasera, S., Rowland, M. J., del Barrio, J., and Scherman, O. A. (2015). Cucurbituril-based molecular recognition. Chem. Rev. 115, 12320-12406. doi: 10.1021/acs.chemrev.5b00341

Böhmer, V. (1995). Calixarenes, macrocycles with (almost) unlimited possibilities. Angew. Chem. Int. Ed. 34, 713-745. doi: 10.1002/anie.199507131

Chen, Y., Sun, S., Lu, D., Shi, Y., and Yao, Y. (2019). Water-soluble supramolecular polymers constructed by macrocycle-based host-guest interactions. Chin. Chem. Lett. 30, 37-43. doi: 10.1016/j.cclet.2018.10.022

Guo, D.-S., and Liu, Y. (2014). Supramolecular chemistry of pSulfonatocalix[n]arenes and its biological applications. Acc. Chem. Res. 47, 1925-1934. doi: 10.1021/ar500009g chlorine dioxide-mediated decomposition of organic pollutants. Chen et al. synthesized and characterized two novel cyclic $\gamma$ peptides with hydrophobic inner surfaces, which could selfassemble into stacking nanotubes through intermolecular $\mathrm{H}$ bonds and $\pi-\pi$ interactions. Notably, the nanotubes could serve as selective water channels to transport water across the lipid membrane. Metallacycles have obtained great interest in recent years. The contribution of Wu et al. constructed two porphyrinbased organoplatinum(II) metallacycles through coordinationdriven self-assembly. Interestingly, these metallacycles could be utilized as catalysts for photo-oxidization with high efficiency. Zhu et al. demonstrated a simple protocol to prepare stimuliresponsive surface-active microcrystalline cellulose particles which are able to reversibly self-assemble at a fluid interface via reversible in situ hydrophobization to stabilize stimuli-responsive Pickering emulsions.

In summary, this Research Topic has highlighted how the fields of macrocyclic and supramolecular chemistry are still inextricably linked. The field has matured considerably in recent years and is now beginning to show more and more potential for real-world applications to address important issues across the sciences.

\section{AUTHOR CONTRIBUTIONS}

All authors listed have made a substantial, direct and intellectual contribution to the work, and approved it for publication.

\section{ACKNOWLEDGMENTS}

We acknowledge financial support by the National Natural Science Foundation of China (21702020, 21801139) and Science Foundation Ireland (SFI) co-funded under the European Regional Development Fund under Grant number 12/RC/2275_P2.
Harada, A., Takashima, Y., and Nakahata, M. (2014). Supramolecular polymeric materials via cyclodextrin-guest interactions. Acc. Chem. Res. 47, 2128-2140. doi: 10.1021/ar500109h

Harada, A., Takashima, Y., and Yamaguchi, H. (2009). Cyclodextrin-based supramolecular polymers. Chem. Soc. Rev. 38, 875-882. doi: 10.1039/B705458K

Kakuta, T., Yamagishi, T.-a., and Ogoshi, T. (2018). Stimuli-responsive supramolecular assemblies constructed from pillar[n]arenes. Acc. Chem. Res. 51, 1656-1666. doi: 10.1021/acs.accounts.8b00157

Lagona, J., Mukhopadhyay, P., Chakrabarti, S., and Isaacs, L. (2005). The Cucurbit[n]uril family. Angew. Chem. Int. Ed. 44, 4844-4870. doi: 10.1002/anie.200460675

Li, S., and Purdy, W. C. (1992). Cyclodextrins and their applications in analytical chemistry. Chem. Rev. 92, 1457-1470. doi: 10.1021/cr00014a009

Murray, J., Kim, K., Ogoshi, T., Yao, W., and Gibb, B. C. (2017). The aqueous supramolecular chemistry of cucurbit[n] urils, pillar[n]arenes and deep-cavity cavitands. Chem. Soc. Rev. 46, 2479-2496. doi: 10.1039/c7cs00095b

Ni, X.-L., Xiao, X., Cong, H., Zhu, Q.-J., Xue, S.-F., and Tao, Z. (2014). Selfassemblies based on the "outer-surface interactions" of Cucurbit[n]urils: new opportunities for supramolecular architectures and materials. Acc.Chem. Res. 47, 1386-1395. doi: 10.1021/ar5000133

Ogoshi, T., Kakuta, T., and Yamagishi, T. A. (2018). Applications of pillar[n]arenebased supramolecular assemblies. Angew. Chem. Int. Ed. 58, 2197-2206. doi: 10.1002/anie.201805884 
Ogoshi, T., Kanai, S., Fujinami, S., Yamagishi, T.-A., and Nakamoto, Y. (2008). Para-bridged symmetrical pillar[5]arenes: their lewis acid catalyzed synthesis and host-guest property. J. Am. Chem. Soc. 130, 5022-5023. doi: $10.1021 /$ ja711260m

Ogoshi, T., Yamagishi, T.-A., and Nakamoto, Y. (2016). Pillar-shaped macrocyclic hosts pillar[n]arenes: new key players for supramolecular chemistry. Chem. Rev. 116, 7937-8002. doi: 10.1021/acs.chemrev.5b00765

Pedersen, C. J. (1967). Cyclic polyethers and their complexes with metal salts. J. Am. Chem. Soc. 89, 7017-7036. doi: 10.1021/ja01002a035

Shinkai, S., Mori, S., Tsubaki, T., Sone, T., and Manabe, O. (1984). New watersoluble host molecules derived from calix[6]arene. Tetrahedron Lett. 25, 5315-5318. doi: 10.1016/S0040-4039(01)81592-6

Strutt, N. L., Zhang, H., Schneebeli, S. T., and Stoddart, J. F. (2014). Functionalizing pillar[n]arenes. Acc. Chem. Res. 47, 2631-2642. doi: 10.1021/ar500177d

Szejtli, J. (1998). Introduction and general overview of cyclodextrin chemistry. Chem. Rev. 98, 1743-1754. doi: 10.1021/cr970022c

Wang, Y., Wang, C., Long, R., Cao, Y., Fan, D., Cen, M., et al. (2019). Synthesis and controllable self-assembly of 3D amphiphilic organoplatinum(ii) metallacages in water. Chem. Commun. 55, 5167-5170. doi: 10.1039/c9cc02173f

Xiao, T., Qi, L., Zhong, W., Lin, C., Wang, R., and Wang, L. (2019c). Stimuli-responsive nanocarriers constructed from pillar[n]arene-based supraamphiphiles. Mater. Chem. Front. 3, 1973-1993. doi: 10.1039/c9qm00428a

Xiao, T., Wang, J., Shen, Y., Bao, C., Li, Z.-Y., Sun, X.-Q., et al. (2021). Preparation of a fixed-tetraphenylethylene motif bridged ditopic benzo-21-crown-7 and its application for constructing AIE supramolecular polymers. Chin. Chem. Lett. doi: 10.1016/j.cclet.2020.10.037. [Epub ahead of print].

Xiao, T., Xu, L., Zhong, W., Zhou, L., Sun, X.-Q., Hu, X.-Y., et al. (2018). Advanced functional materials constructed from pillar[n]arenes. Isr. J. Chem. 58, 1183-1193. doi: 10.1002/ijch.201800026

Xiao, T., Xu, L., Zhou, L., Sun, X.-Q., Lin, C., and Wang, L. (2019d). Dynamic hydrogels mediated by macrocyclic host-guest interactions. J. Mater. Chem. B 7, 1526-1540. doi: 10.1039/C8TB02339E

Xiao, T., Zhong, W., Xu, L., Sun, X.-Q., Hu, X.-Y., and Wang, L. (2019b). Supramolecular vesicles based on pillar[n]arenes: design, construction, and applications. Org. Biomol. Chem. 17, 1336-1350. doi: 10.1039/C8OB 03095B

Xiao, T., Zhong, W., Zhou, L., Xu, L., Sun, X.-Q., Elmes, R. B. P., et al. (2019e). Artificial light-harvesting systems fabricated by supramolecular host-guest interactions. Chin. Chem. Lett. 30, 31-36. doi: 10.1016/j.cclet.2018.05.034

Xiao, T., Zhou, L., Sun, X.-Q., Huang, F., Lin, C., and Wang, L. (2020b). Supramolecular polymers fabricated by orthogonal self-assembly based on multiple hydrogen bonding and macrocyclic host-guest interactions. Chin. Chem. Lett. 31, 1-9. doi: 10.1016/j.cclet.2019.05.011

Xiao, T., Zhou, L., Wei, X., Li, Z., and Sun, X. (2020a). Supramolecular copolymers driven by quadruple hydrogen bonding and host-guest interactions. Chin. J. Org. Chem. 40, 944-949. doi: 10.6023/cjoc201911014

Xiao, T., Zhou, L., Xu, L., Zhong, W., Zhao, W., Sun, X.-Q., et al. (2019a). Dynamic materials fabricated from water soluble pillar[n]arenes bearing triethylene oxide groups. Chin. Chem. Lett. 30, 271-276. doi: 10.1016/j.cclet.2018.05.039

Xue, M., Yang, Y., Chi, X., Zhang, Z., and Huang, F. (2012). Pillararenes, a new class of macrocycles for supramolecular chemistry. Acc. Chem. Res. 45, 1294-1308. doi: 10.1021/ar2003418

Zhang, C., Li, S., Zhang, J., Zhu, K., Li, N., and Huang, F. (2007). Benzo-21-crown7/secondary dialkylammonium salt [2]pseudorotaxane- and [2] rotaxane-type threaded structures. Org. Lett. 9, 5553-5556. doi: 10.1021/ol702510c

Conflict of Interest: The authors declare that the research was conducted in the absence of any commercial or financial relationships that could be construed as a potential conflict of interest.

The handling editor declared a past co-authorship with one of the authors RE.

Copyright (c) 2020 Xiao, Elmes and Yao. This is an open-access article distributed under the terms of the Creative Commons Attribution License (CC BY). The use, distribution or reproduction in other forums is permitted, provided the original author(s) and the copyright owner(s) are credited and that the original publication in this journal is cited, in accordance with accepted academic practice. No use, distribution or reproduction is permitted which does not comply with these terms. 